This is the author's final, peer-reviewed manuscript as accepted for publication. The publisher-formatted version may be available through the publisher's web site or your institution's library.

\title{
A new variant of antimetabolic protein, arcelin from an Indian bean, Lablab purpureus (Linn.) and its effect on the stored product pest, Callosobruchus maculatus
}

Janarthanan Sundaram, Sakthivelkumar Shanmugavel, Veeramani Velayutham, Radhika Dixit, Subbaratnam Muthukrishanan

\section{How to cite this manuscript}

If you make reference to this version of the manuscript, use the following information:

Sundaram, J., Shanmugavel, S., Velayutham, V., Dixit, R., \& Muthukrishanan, S. (2012). A new variant of antimetabolic protein, arcelin from an Indian bean, Lablab purpureus (Linn.) and its effect on the stored product pest, Callosobruchus maculatus. Retrieved from http://krex.ksu.edu

\section{Published Version Information}

Citation: Sundaram, J., Shanmugavel, S., Velayutham, V., Dixit, R., \& Subbaratnam, M. (2012). A new variant of antimetabolic protein, arcelin from an Indian bean, Lablab purpureus (Linn.) and its effect on the stored product pest, Callosobruchus maculatus. Food Chemistry, 135(4), 2839-2844.

Copyright: (C) 2012 Elsevier Ltd.

Digital Object Identifier (DOI): doi:10.1016/j.foodchem.2012.06.129

Publisher's Link: http://www.sciencedirect.com/science/article/pii/S0308814612012009

This item was retrieved from the K-State Research Exchange (K-REx), the institutional repository of Kansas State University. K-REx is available at http://krex.ksu.edu 


\title{
A new variant of antimetabolic protein, arcelin from an Indian bean, Lablab purpureus (Linn.) and its effect on the stored product pest, Callosobruchus maculatus
}

\author{
Janarthanan Sundaram ${ }^{\text {a, }}$, Sakthivelkumar Shanmugavel ${ }^{\text {a }}$, Veeramani \\ Velayutham $^{\text {a }}$, Radhika Dixit ${ }^{\text {b }}$, Subbaratnam Muthukrishanan ${ }^{\text {b }}$ \\ ${ }^{a}$ Department of Zoology, University of Madras, Guindy Campus, Chennai-600025, India \\ ${ }^{b}$ Department of Biochemistry, Kansas State University, Manhattan, KS 66506, U.S.A
}

\begin{abstract}
*Corresponding author. Address: Unit of Entomology, Department of Zoology, University of Madras, Life Sciences Building, Guindy Campus, Chennai 600 025, Tamil Nadu, India. Tel.: +91 44 22202841; Fax: +91-44- 22352494

E.mail: janas_09@yahoo.co.in
\end{abstract}

\begin{abstract}
The anti-metabolic or insecticidal gene, arcelin (Arl) was isolated, cloned and sequenced using sequence specific degenerate primers from the seeds of Lablab purpureus collected from the Western Ghats, Tamil Nadu, India. The L. purpureus arcelin nucleotide sequence was homologous to Arl-3 and Arl-4 alleles from Phaseolus spp. The protein it encodes has $70 \%$ amino acid identity with the amino acid sequences of Arl-3I, Arl-3III, Arl-4 precursor, Arl-4 and Arl-4I. The partially purified arcelin from the seeds of $L$. purpureus using artificial diet confirmed the complete retardation of development of the stored product pest Callosobruchus maculatus at $0.2 \% \mathrm{w} / \mathrm{w}$ arcelin-incorporated artificial seeds.
\end{abstract}

Keywords: Insecticidal protein, Arcelin, Pulse, Lablab purpureus, Callosobruchus maculatus 


\section{Introduction}

In a continuing search for new plant genes that confer insect resistance, some exciting molecules have been found in the gene family of lectin and lectin-like proteins in the common bean, Phaseolus vulgaris (Chrispeels, 1997). Different members of this family are thought to be toxic towards insects of stored product pests belonging to the coleopteran family of Bruchidae that commonly infest leguminous seeds and form the basis for post harvest losses. The lectin gene family in P. vulgaris consists of true lectin, phytohemagglutinins (PHA) (both E and L variants) and lectin-like proteins called alpha amylase inhibitors and arcelin (Goossens et al., 2000). PHA was the first member of this family to which insecticidal properties were well demonstrated (Janzen, Juster, \& Liener, 1976). Later it was revealed that the deleterious effects on the cowpea weevil, Callosobruchus maculatus were shown to be not only due to PHA, but to a contamination with the bean alpha amylase inhibitor $(\alpha-\mathrm{AI})$ (Huesing, Shade, Chrispeels, \& Murdock, 1991). It was proved subsequently that the $\alpha$-AI displayed relatively high toxicity levels, not only to some bruchid species, but also to members of other insect families (Ishimoto \& Kitamura, 1989; Ishimoto, Sato, Chrispeels, \& Kitamura, 1996; Schroeder et al., 1995). Interestingly, novel $\alpha$-AI variants with insecticidal effects were isolated from some P. vulgaris genotypes (Ishimoto \& Chrispeels, 1996). Then, arcelin was identified being associated with the resistant phenotypes of P. vulgaris (Osborn, Alexander, Sun, Cardona, \& Bliss, 1988).

The insecticidal protein, arcelin(s) found in some wild accessions of the common bean, $P$. vulgaris, have been known to confer resistance against bruchid beetles. It was reported that the amino acid sequence of arcelins showed homology with two other phytohemagglutinin proteins (PHA-L and PHA-E) and $\alpha$-amylase inhibitors (Chrispeels \& Raikhel, 1991). It was then observed that the members of this protein family, though displaying similar tertiary structures, differ in their biochemical properties, glycosylation patterns, quaternary structures and sugar binding specificities (Fabre et al., 1998; Mourey 
et al., 1998). Seven arcelin allelic variants (Arcelin 1-7) have been described with molecular weight in the range of 27-42 kDa (Acosta-Gallegos et al., 1998; Janarthanan, Suresh, Radke, Morgan, \& Oppert, 2008; Osborn, Blake, Gepts, \& Bliss, 1986; Santino, Valesina, Lioi, Vitale, \& Bollini, 1991). Among these seven arcelin allelic variants, arc-1

and arc-5 are reported to be conferring the highest resistance to the bruchid pests (Fory et al., 1996). Each arcelin variant is composed of several polypeptides presumably encoded by a family of different genes (Hartweck, Vogelzang, \& Osborn, 1991). The importance of arcelin in the present perspective is its insecticidal property and in particular their inhibitory activity on larval development in stored product pests (Cardona, Kornegay, Posso, Morales, \& Ramirez, 1990; Janarthanan \& Suresh, 2003; Janarthanan et al., 2008). In this paper arcelin is isolated from the seeds of an Indian wild pulse variety, Lablab purpureus, a new source of this insecticidal gene, and its antibiotic efficacy on the stored product pest, C. maculates is verified.

\section{Material and Methods}

\subsection{Isolation of RNA and cDNA synthesis}

Seeds of wild L. purpureus were soaked in water for $48 \mathrm{~h}$ and then placed on petriplates containing moistened cotton for a few days. The seed coat was removed, and embryos (including epi- and hypocotyls and cotyledons) were collected. The samples $(50 \mathrm{mg})$ were immediately frozen with liquid nitrogen and ground in RNase free microcentrifuge tubes.

Total RNA was isolated (RNeasy, Qiagen, USA) from frozen and ground tissue. $450 \mu \mathrm{L}$ of RNeasy lysis buffer (RLT buffer) was added to the powdered tissue (50 mg) and vortexed vigorously, centrifuged for $3 \mathrm{~min}$ at 10,000 rpm and the supernatant was collected. The supernatant was added to 0.5 volumes $(225 \mu \mathrm{L})$ of $95 \%$ ethanol and mixed immediately by pipetting. Immediately, the sample was applied to an RNeasy mini column placed in a $2 \mathrm{~mL}$ collection tube and was centrifuged for $15 \mathrm{~min}$ at 10,000 rpm and the flow-through was discarded. To the column $700 \mu \mathrm{L}$ of RNeasy wash buffer 1 (RW1 buffer) was added, the tube was closed gently and was centrifuged for $15 \mathrm{~s}$ at 
$10,000 \mathrm{rpm}$ to wash the column. The column was transferred to a new $2 \mathrm{~mL}$ collection tube and $500 \mu \mathrm{L}$ of RNeasy wash buffer with ethanol (RPE buffer) was added. The tube was closed gently and centrifuged for $15 \mathrm{~s}$ at 10,000 rpm. The flow through was discarded and $500 \mu \mathrm{L}$ RNeasy wash buffer with ethanol (RPE buffer) was added again to the column, and it was centrifuged for $2 \mathrm{~min}$ at $10,000 \mathrm{rpm}$ to dry the RNeasy silica gel membrane. The column was now transferred to a new $1.5 \mathrm{~mL}$ collection tube, and RNAse free water $(30-50 \mu \mathrm{L})$ was added directly to the silica gel membrane. The lid was closed gently, centrifuged for $1 \mathrm{~min}$ at $10,000 \mathrm{rpm}$ to elute the RNA and stored at $-80^{\circ} \mathrm{C}$.

The Superscript III RT-Invitrogen kit was used for cDNA synthesis. A $20 \mu \mathrm{L}$ reaction volume (full scale) containing $1.0 \mu \mathrm{L}$ of Oligo dT $\left(50 \mu \mathrm{mol} \mathrm{L}{ }^{-1}\right), 8.0 \mu \mathrm{l}$ of RNA $(5 \mu \mathrm{g})$ and $1.0 \mu \mathrm{L}$ of $\mathrm{dNTP}\left(10 \mathrm{mmol} \mathrm{L}^{-1}\right.$ each dNTP) was prepared. The mixture was incubated at $65{ }^{\circ} \mathrm{C}$ for $5 \mathrm{~min}$ and then placed on ice for $2 \mathrm{~min}$. It was briefly $(20 \mathrm{~s})$ centrifuged to collect the content of the tube. Then $2.0 \mu \mathrm{L}$ of $10 \times$ RT buffer, $4.0 \mu \mathrm{L}$ of $\mathrm{MgCl}_{2}\left(25 \mathrm{mmol} \mathrm{L}^{-1}\right), 2.0 \mu \mathrm{L}$ of DTT $\left(0.1 \mathrm{mmol} \mathrm{L}^{-1}\right)$ and $1.0 \mu \mathrm{L}$ of RNase out (RNase inhibitor) were added to the tube. The contents were preheated at $45^{\circ} \mathrm{C}$ for $2 \mathrm{~min}$. Then the enzyme-Superscript III RT $(1.0 \mu \mathrm{L}-200$ units/ $\mu \mathrm{L})$ was added. The tube was incubated at $45{ }^{\circ} \mathrm{C}$ for $50 \mathrm{~min}$. The reaction was stopped by heat shock at $85{ }^{\circ} \mathrm{C}$ for 5 min. The tube was chilled on ice for approximately for $30 \mathrm{~min}$. It was then briefly centrifuged to collect the contents. RNase H (1.0 $\mu \mathrm{L}$ E. coli RNase H - 2 units) was added to the tube to remove RNA complementary to cDNA. It was incubated further at $37{ }^{\circ} \mathrm{C}$ for $20 \mathrm{~min}$ and stored at $-20{ }^{\circ} \mathrm{C}$.

\subsection{Designing degenerate primers and amplification of L. purpureus arcelin gene}

The design of degenerate primers was based on regions specific for arcelin, as was determined by MALDI-TOF and N-terminal sequencing of arcelin purified from Lablab purpureus (Janarthanan et al., 2008). Specific degenerate oligonucleotide primers designed were: LpArcF: 5'-GCC AGC GAA ACC TCC-3'; LpArcR: 5'-ACC AAG AGA GCA CGT C-3'. PCR reagents (Takara, USA) were added to the PCR reaction tube to a 
final volume of $25 \mu \mathrm{L}$. The reaction mixture was heated (initial denaturation) for $2 \mathrm{~min}$ at $94{ }^{\circ} \mathrm{C}$ in a thermal cycler (Master Cycler, MJ Research, and USA.). PCR was performed for 30 cycles at a denaturation of $94{ }^{\circ} \mathrm{C}$ for $2 \mathrm{~min}$, annealing at $51{ }^{\circ} \mathrm{C}$ for $1 \mathrm{~min}$, and extension at $72{ }^{\circ} \mathrm{C}$ for $1 \mathrm{~min}$. Final extension was at $72{ }^{\circ} \mathrm{C}$ for $10 \mathrm{~min}$, and the product was stored at $4{ }^{\circ} \mathrm{C}$ for $30 \mathrm{~min}$. The amplified product was analyzed using $1 \%$ agarose gel.

\subsection{Cloning and sequencing of arcelin gene}

$30 \mu \mathrm{L}$ of water was added to $20 \mu \mathrm{L}$ of the PCR product, followed by addition of $50 \mu \mathrm{L}$ of phenol-chloroform. The sample was vortexed gently. The tube was centrifuged at $10,000 \mathrm{rpm}$ for $2 \mathrm{~min}$. The aqueous supernatant was collected in a new tube and $10 \mu \mathrm{L}$ of $2 \mathrm{mmol} \mathrm{L}^{-1}$ ammonium acetate was added. $125 \mu \mathrm{L}$ of $100 \%$ ethanol was added to the tube, and the sample was stored overnight at $-20^{\circ} \mathrm{C}$. The tube was centrifuged at 13,000 rpm for 12 min at $4{ }^{\circ} \mathrm{C}$, the supernatant was removed and the product was washed with $70 \%$ ethanol by inverting the tubes three times, centrifuging each time $3 \mathrm{~min}$ at $4{ }^{\circ} \mathrm{C}$. The supernatant was removed and the tube was inverted onto a clean tissue to remove ethanol. The pellet was dissolved in $25 \mu \mathrm{L}$ of RNase free water and was briefly vortexed and centrifuged. The purified PCR product was analyzed on a $1 \%$ agarose gel. The product was cloned into pGEMT vector (Promega, Madison, WI) and subsequently four independent clones were sequenced in both directions. For each bacterial colony, PCR was performed for rapid detection of transformation success and determination of correct ligation products by size. Primers for the specific sequence (pGEMT vector) were used for preparing the PCR reaction mix. Colonies were selected and numbered on the bottom side of the plate. The PCR mix was added to the PCR tubes ( $10 \mu \mathrm{L} /$ reaction) kept on ice without adding the colony. Using a pipette tip, the selected colonies were touched on its side and the tip stirred in the PCR mix and amplified by PCR. Plasmid DNA was isolated (Plasmid Miniprep, Promega) and was used to transform JM109 high efficiency competent cells (Promega). The steps described in Wizard plus Plasmid Miniprep (Promega) using the Magic Minipreps (TM) system was used to isolate plasmid DNA 
from the cultures of $E$. coli. The plasmid with arcelin insert was sequenced utilizing the gene sequencing facility of Kansas State University, USA.

\subsection{Insect bioassay}

Partially purified arcelin as described in our earlier paper (Janarthanan et al., 2008) was incorporated into the artificial seeds using four different concentrations of arcelin $(0.05 \%, 0.1 \%, 0.15 \%$ and $0.2 \%)$ by following the method of Shade et al. (1994). The susceptible cowpea seeds (Vigna unguiculata) were milled into a powder. The resulting flour was mixed with water in a 1:1 ratio and was stirred until a smooth paste was formed. The paste was then transferred to a $10 \mathrm{ml}$ syringe and injected directly into the wells of a microtitre plates. These plates were frozen at $-20^{\circ} \mathrm{C}$ for $1 \mathrm{~h}$ and lyophilized for $24 \mathrm{~h}$. After lyophilization, the solid artificial seeds were removed from the wells of the microtitre plates by gentle pressure from the bottom side of the plates. The seeds were then placed in plastic Petri plates and maintained for hydration at a constant temperature $\left(25^{\circ} \mathrm{C}\right)$ and relative humidity $(60 \pm 5 \%)$ for $48 \mathrm{~h}$. During hydration, the plates were closed with fine mesh to prevent accidental infestation. The artificial seeds (10 number of seeds/treatment) were placed in glass jars for C. maculatus infestation. Newly emerged adults ( 2 pairs of adult males and females) were introduced into the glass jars for oviposition. The insects were allowed to stay in the jars for 4 days. Effect of various doses of arcelin on oviposition, post-embryonic development period, adult emergence and percent infestation/seed damage were studied. 
Fig. 1. A fragment amplified at $651 \mathrm{bp}$ using the cDNA with arcelin specific degenerate primers at various annealing temperatures of $50{ }^{\circ} \mathrm{C}$ (lane 1), $50.9{ }^{\circ} \mathrm{C}$ (lane 2), $52{ }^{\circ} \mathrm{C}$ (lane 3 ) and $53.2{ }^{\circ} \mathrm{C}$ (lane 4). Lane M: 100 bp DNA ladder.

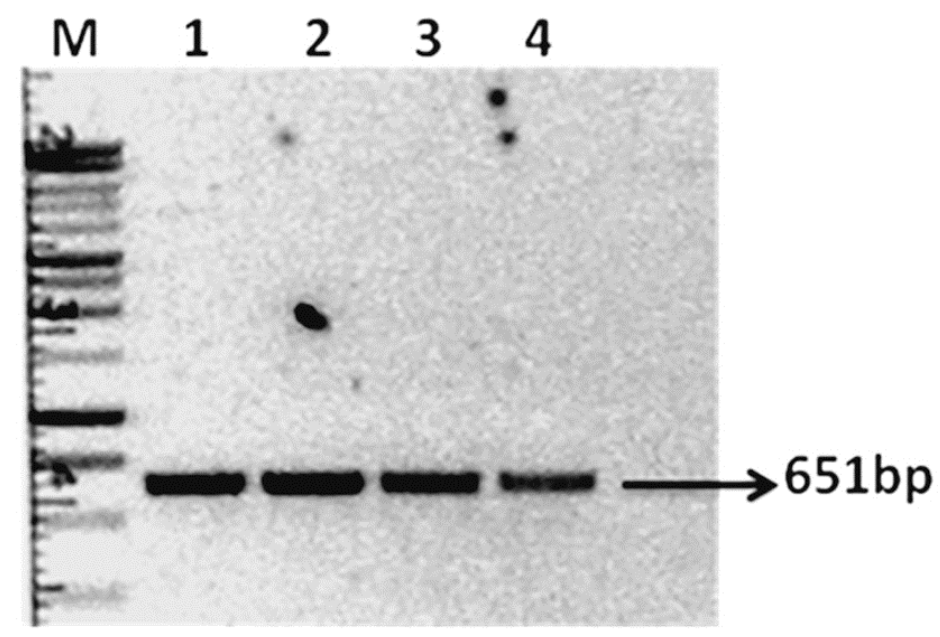

\section{Results}

The partially purified arcelin was resolved in a tricine gel under reducing conditions of electrophoresis. The three visible arcelin sub-unit fractions were subjected to trypsin digestion and the peptides were identified by MALDI TOF-MS. The analyses revealed sequences of two internal peptides (for major fraction 2) and one of the sequences, D V L S W was aligned with the deduced amino acid sequences at the carboxyl terminus of arcelin genes of Phaseolus. Arcelin was again subjected to tricine gel electrophoresis and blotted onto membrane for $\mathrm{N}$-terminal sequencing. The $\mathrm{N}$-terminal sequence of the arcelin polypeptide fractions revealed the presence of one polypeptide sequence namely, A S E T S in arcelin 3, 4 and 5 of Phaseolus vulgaris.

Based on the internal peptide sequences of arcelin obtained from MALDI TOF-MS and N-terminal sequencing, degenerate primers were designed. They were used to carry out reverse transcription PCR reaction on total RNA isolated from seeds of L. purpureus. An incomplete or a partial fragment of $651 \mathrm{bp}$ was amplified using these degenerate primers (Fig. 1). The fragment was then cloned in pGEMT vector and transformed using JM109 competent cells (Promega). A colony PCR was performed to 
confirm the cloned fragment of arcelin gene in the vector (data not shown). Randomly selected clones were used to isolate plasmid DNA and sequenced. After sequencing, the cDNA sequences for 4 clones were obtained and they revealed their identity at the DNA level at $98 \%$ (Fig.2).

The amino acid sequence was deduced using the partial nucleotide sequences of arcelin from L. purpureus seeds that were composed of 217 amino acids. The deduced peptide sequence of $L$. purpureus arcelin was matched exactly with amino acid sequences of arcelin 3 and 4 of Phaseolus (Figs. 3 and 4). They were then subjected to ExPASY proteomics tools to identify the nature of the protein. The analysis revealed that there were consensus sequences for legume lectins alpha, beta signatures and sequences for $\mathrm{N}$-glycosylation sites in the deduced L. purpureus arcelin gene (Fig. 5).

These partially purified arcelin was tested for their efficacy on the growth and development of the stored product pest, C. maculates, using artificial seeds. The adult emergence was significantly reduced in all the treatments and was absent in seeds containing $0.2 \%$ arcelin. The infestation potential was also drastically reduced in all the treatments when compared to control group (Table 1). The bioassay results suggest the toxic nature of the arcelin isolated from the wild seeds of $L$. purpureus.

\section{Discussion}

Arcelins in wild common beans belong to the lectin-like family of seed storage proteins. They contain polypeptides closely related to phytoheamagglutinins (PHA) and alpha-amylase inhibitors ( $\alpha$-AIs). Arcelins like PHA demonstrate a weak carbohydratebinding activity and have a different intrinsic specificity for complex sugars, which leads to a mechanism of toxicity to bruchid beetles (Fabre et al., 1998). The toxic properties of arcelins were related to their recognition and interaction with various glycoproteins and other constituents of the digestive tract membranes, as well as direct binding to intestinal cells of the insects (Fabre et al., 1998; Minney et al., 1990; Paes et al., 2000).

Arcelins were first reported in some wild common Phaseolus bean accessions from Mexico (Osborn, Alexander, et al., 1988; Osborn, Burow, \& Bliss, 1988). Some tepary beans are also known to contain variants of arcelin proteins. This protein is absent in cultivated common Phaseolus beans (Chrispeels \& Raikhel, 1991) most probably due 
to domestication process. In a way similar that of PHA and $\alpha$-AIs, arcelins also formed as a result of independent duplication events of lectins, which evolved into a number of variants. In the genotypes of bean with high arcelin levels, they normally replace a proportion of phaseolin (Hartweck \& Osborn, 1997; Minney et al., 1990). Seeds that accumulate large quantities of arcelins or its variants are likely to be more resistant to bruchid infestation. In a preliminary study in the present investigation (data not shown) the insect bioassay was performed with whole seeds of $L$. purpureus, not infested by the stored product pest, C. maculatus. This prompted for the further work to identify, isolate and characterize the anti-metabolic or antibiosis compound arcelin from the wild seeds of L. purpureus. A partially purified arcelin and its characterization lead to the amplification of a gene encoding arcelin.

Fig. 2. Partial L. purpureus arcelin cDNA sequence (651 bp). The degenerate primer sequences are indicated as red coloration at 3' and 5' regions.

5'TACCAAGAGAGCACGTCGTGCGTTTCCTCGTATGCTGAGGTGGCAGAGAACCCAACGCTCA CCCAGTCGTCAAGAACTTTCTCCAGCTCCACATTTGCAGAGACGTGGTATCTCTTTCTCGGAAT AGGGTAAAACAGAGAAACCGCCAAGAACTTCGTGGAGGAGTCATAGGTGATCCGAACATCGG CATTTTGTCCGATGTAGTGGCGGAAATTCCAAGGCACGCTTCCGATAGGCTGGATGGAGTTCA CGTCGATGCCAATACGGTTGCTGAAGGTGTCGAACACCACAGCCACAGTATGGGCGTTTATAT CGTTTTCGGATTTGTTGAAAAGACCTAGAAGACGGCCTTTTTTTTTGGGCTGAGAGTCGACGG GGACGAGAGCAAAGGCAAGGCCATAGCCGGACATTAATTTGTTGGCAGGGAGGATATTGAAT GTGAAGTTGGTGTCGAAGCTCGCGTTGCCGGTGCTGTCCCTCATTTGGATGGGGGCGGAGTAC AAGGCGCGGCCCATAGAGTCCACACTGGGTTCTCCGTTGTGTGTAACATTGGTTAGTAGTAAG TGGCCTTTGAATGAGACGGTGGCATTGCCTTGGAGGATAAGGTTGGTTTCGTTGAACCTATTG ATTTCGAAGGAGGTTTCGCTGGCA3'

There are seven arcelin variants described so far from various wild accessions of the common bean Phaseolus based on their amino acid sequences. They are well-known by distinct electrophoretic polypeptide profiles that range from 31 to $40 \mathrm{kDa}$ in size. The variants are genetically different alleles of the same locus revealed by various workers: Arl-1, Arl-2, Arl-3, and Arl-4 (Hartweck et al., 1991; Osborn, Alexander, et al., 1988; Osborn et al., 1986), Arl-5 (Goossens, Geremia, Bauw, Van Montagu, \& Angenon, 1994), Arl-6 (Santino et al., 1991) and Arl-7 (Acosta-Gallegos et al., 1998). Out of the seven arcelin variants, six are grouped into three clusters based on cDNA sequence homology (Sparvoli \& Bollini, 1998; Sparvoli, Lanave, Santucci, Bollini, \& Lioi, 2001). Arl-1, Arl-2 and Arl-6, contribute to the same cluster while a second group is composed 
of Arl-3 and Arl-4, the most ancient variants. Arl-5 has isoforms 5a and 5b forms a separate branch. In the present investigation, an arcelin isoform identified in an Indian wild bean L. purpureus and its partial nucleotide sequence (651bp) was homologous to Arl-3 (801bp) and Arl-4 (801bp) alleles from Phaseolus spp. The protein it encodes had $70 \%$ amino acid identity with the amino acid sequences of Arl-3I, Arl-3III, Arl-4 precursor, Arl-4 and Arl-4I. This is the first report that the seed of Indian wild bean $L$. purpureus possesses antibiosis activity against the stored product insect pest, $C$. maculates.

Fig. 3. Multiple sequence alignment of most similar amino acid sequences with the deduced amino acid sequence of $L$. purpureus. The most conserved regions are indicated in rectangular boxes.

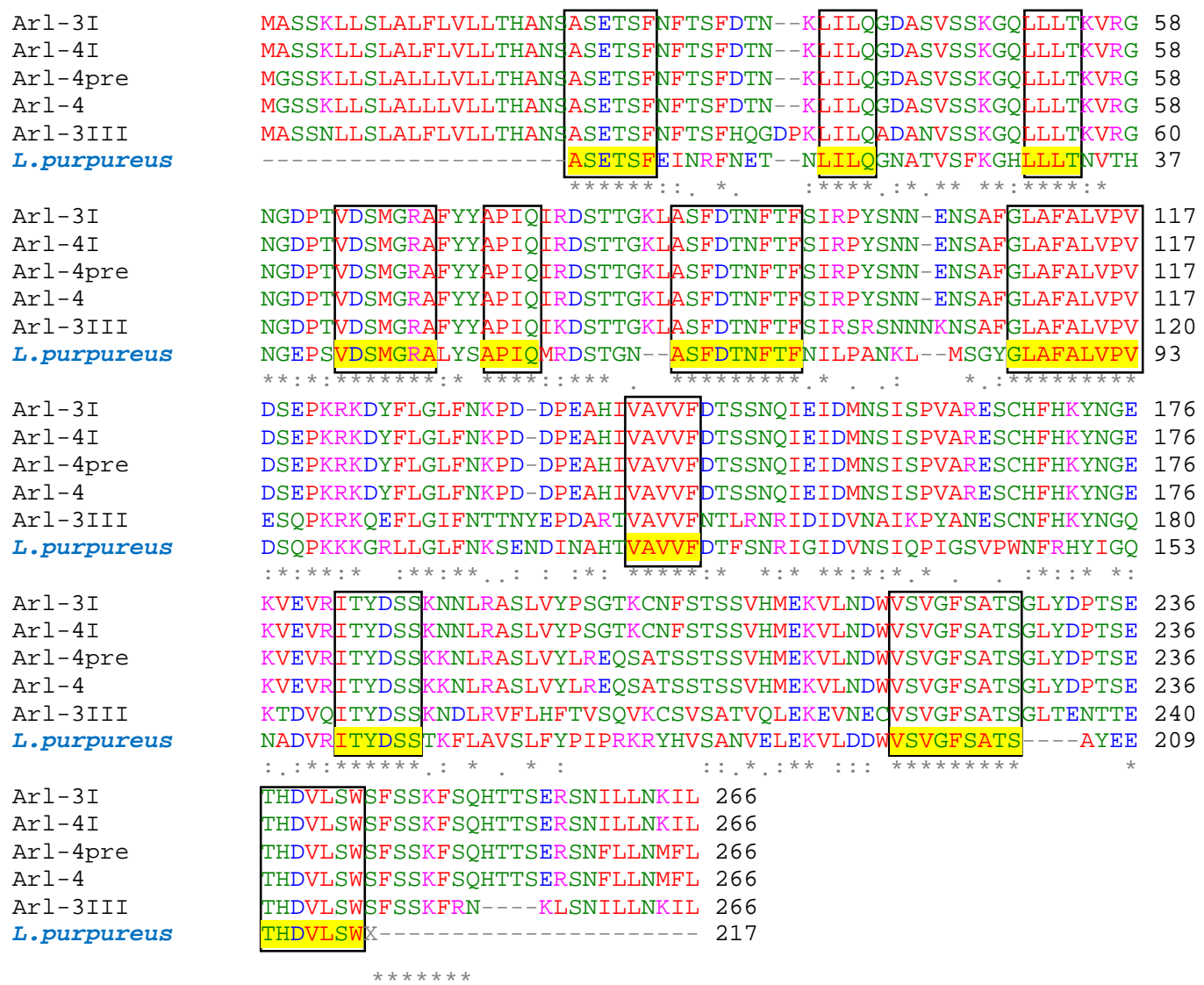

The seeds of Phaseolus containing diverse variants of arcelins demonstrate different levels of resistance to stored product insects which is illustrated by delay in adult emergence, reduced adult weight and reduction in number of adults emergence as demonstrated in bruchid infestation studies with different bean accessions (Acosta- 
Gallegos et al., 1998; Cardona et al., 1990; Kornegay \& Cardona, 1991; Kornegay, Cardona, \& Posso, 1993). These studies found that some arcelin variants are more effective than others against bruchids, where bean genotypes containing Arl-1, Arl-2, Arl3 and Arl-4 demonstrated variable antibiosis effects to Zabrotes subfasciatus. Different arcelin variants from wild common bean accessions have been backcrossed into cultivated lines to improve resistance to bruchids (Cardona et al., 1990; Hartweck, Cardona, \& Osborn, 1997; Kornegay et al., 1993; Osborn, Alexander, et al., 1988). Of the seven arcelin variants, only lines containing Arl-1, Arl-2, Arl-4 and Arl-5 demonstrated resistance to Acanthoscelides obtectus while genotypes containing other arcelin variants conferred no resistance to A. obtectus (Fory et al., 1996; Kornegay \& Cardona, 1991; Paes et al., 2000). The partially purified arcelin-incorporated artificial seeds through feeding bioassay studies in the present study were found to be resistant to C. maculatus infestation and at $0.2 \%(\mathrm{w} / \mathrm{w})$ arcelin in the diet completely inhibited the development of insects. The mechanism of toxicity of arcelin from P. vulgaris to the larvae of Zabrotes subfasciatus studied earlier (Minney et al., 1990) revealed the antimetabolic nature and also indigestibility of arcelin by gut proteases in the insect. Later, our investigation of arcelin with the storage pests Rhyzopertha dominica (internal feeder of grain) and Oryzaephilus surinamensis (external feeder of grain) demonstrated retarded development of these grain feeders at $2 \%$ in the diet and complete mortality of all larvae in both species at 5\% dose (Janarthanan et al., 2008). Hence, the insecticidal gene-arcelin identified in the seeds of Indian wild pulse L. purpureus could be used as a tool for the development of transgenic plant in future.

Fig. 4. Boost trap Phylogram NJ Tree - Protein sequences of arcelin 3 and 4 with $L$. purpureus amino acid sequence.

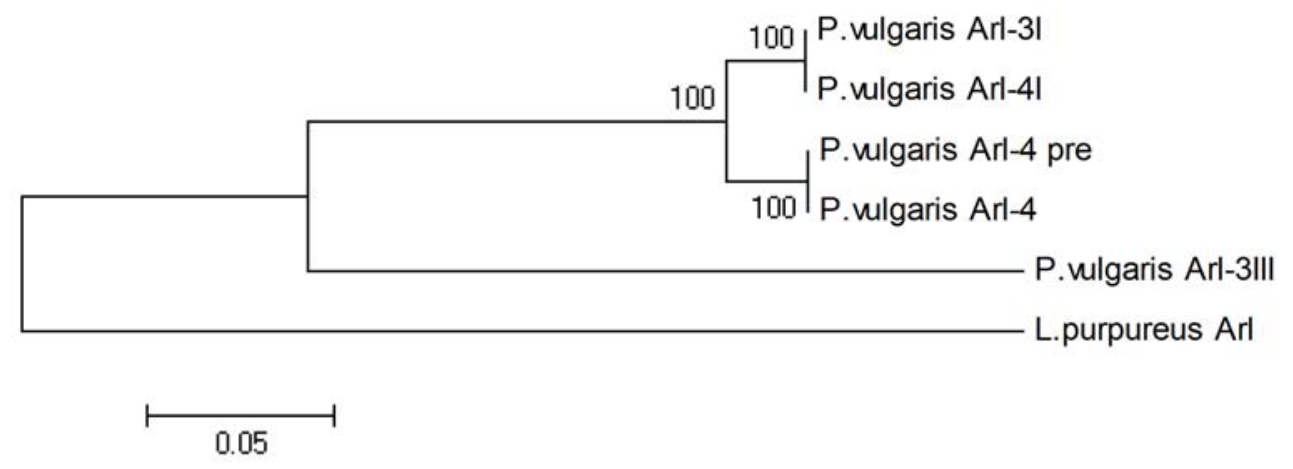


Fig. 5. Deduced L. purpureus amino acid sequence with consensus sequences for legume lectin alpha, beta chain signatures and N-glycosylation sites.

\section{ASETSFEINRFNETNLILQGNATVSFKGHLLLTNVTHNGEPSVDSMGRALYSAPIQ} MRDSTGNASFDTNFTFNILPANKLMSGYGLAFALVPVDSQPKKKGRLLGLFNKS ENDINAHTVAVVFDTFSNRIGIDVNSIQPIGSVPWNFRHYIGQNADVRITYDSSTK FLAVSLFYPIPRKRYHVSANVELEKVLDDWVSVGFSATSAYEETHDVLSWX

LDDWVSVGFS: Consensus sequences for legume lectins alpha chain signatures

VAVVFDT: Consensus sequences for legume lectins beta chain signatures

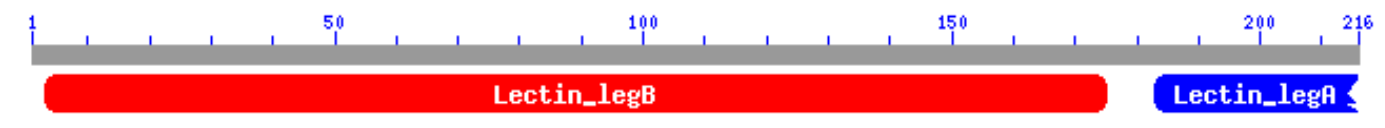

NETN, NATV, NVTH, NASF, NFTF \& NKSE: N-glycosylation sites

ASETS: N-terminal peptide sequence of arcelin

DVLSW: Internal peptide sequence of arcelin using MALDI-TOF

Table 1

Effect of partially purified arcelin on C. maculatus.

\begin{tabular}{ccccc}
\hline $\begin{array}{c}\text { Artificial seeds } \\
\text { with arcelin } \\
(\% \mathrm{w} / \mathrm{w})\end{array}$ & Oviposition & $\begin{array}{c}\text { Adult } \\
\text { emergence } \\
(\%)\end{array}$ & $\begin{array}{c}\text { Developmental } \\
\text { period (days) }\end{array}$ & $\begin{array}{c}\text { Infestation } \\
(\%)\end{array}$ \\
\hline $\begin{array}{c}0.00 \\
(\text { Control })\end{array}$ & $22 \pm 03.6$ & 100 & $26 \pm 0.6$ & 23 \\
0.05 & $24 \pm 04.2$ & $80^{\mathrm{a}}$ & $26 \pm 0.4$ & $11^{\mathrm{a}}$ \\
0.10 & $14 \pm 02.8$ & $28^{\mathrm{a}}$ & $29 \pm 1.2$ & $08^{\mathrm{a}}$ \\
0.15 & $18 \pm 05.1$ & $36^{\mathrm{a}}$ & $33 \pm 0.8$ & $04^{\mathrm{a}}$ \\
0.20 & $20 \pm 04.2$ & Nil & - & - \\
\hline
\end{tabular}

Data obtained were mean \pm SD of three replications.

${ }^{a}$ Significantly different from control at 0.05 level, according to the Fisher exact test. 


\section{Acknowledgement}

This work was supported by the Department of Biotechnology, Ministry of Science and Technology, Government of India, for the Overseas Associateship Award to S. Janarthanan. The first author gratefully acknowledges Dr. Brenda Oppert, Research Molecular Biologist, GMPRC, USDA, Manhattan, KS for providing Overseas Associateship position in her laboratory.

\section{References}

Acosta-Gallegos, J. A., Quintero, C., Vargas, J., Toro, O., Tohme, J., \& Cardona, C. (1998). A new variant of arcelin in wild common bean, Phaseolus vulgaris L., from southern Mexico. Genetic Resources and Crop Evolution, 45, 235-242.

Cardona, C., Kornegay, J., Posso, C., Morales, F., \& Ramirez. H. (1990). Comparative value of four arcelin variants in the development of dry bean lines resistance to the Mexican bean weevil. Entomologia Experimentalis et Applicata, 56, 197-206.

Chrispeels, M. J. (1997). Transfer of bruchid resistance from the common bean to other starchy grain legumes by genetic engineering with the a-amylase inhibitor gene. In N. Carozzi \& M. Koziel (Eds.), Advances in insect control: The role of transgenic plants (pp. 139-156). Taylor and Francis

Chrispeels, M. J., \& Raikhel, N. V. (1991). Lectins, lectin genes and their role in plant defense. Plant Cell, 3, 1-9.

Fabre, C., Causse, H., Mourey, L., Koninkx, J., Riviere, M., Hendriks, H., et al. (1998). Characterization and sugar-binding properties of arcelin-1, an insecticidal lectinlike protein isolated from kidney bean (Phaseolus vulgaris L. cv.RAZ-2) seeds. Biochemical Journal, 329, 551-560.

Fory, L. F., Finardi-Filho, F., Quintero, C. M., Osborn, T. C., Cardona, C., Chrispeels, M. J., et al. (1996). $\alpha$-Amylase inhibitors in resistance of common beans to the Mexican bean weevil and the bean weevil (Coleoptera: Bruchidae). Journal of Economic Entomology, 89, 204-210. 
Goossens, A., Geremia, R., Bauw, G., Van Montagu, M., \& Angenon, G. (1994). Isolation and characterization of arcelin 5 proteins and cDNA. European Journal of Biochemistry, 225, 787-795.

Goossens, A., Quintero, C., Dillen, W., De Rycke, R., Valor, J. F., De Clercq, J., et al. (2000). Analysis of bruchid resistance in the wild common bean accession G02771: no evidence for insecticidal activity of arcelin 5. Journal of Experimental Botany, 51, 1229-1236.

Hartweck, L. M., Cardona, C., \& Osborn, T. C. (1997). Bruchid resistance of common bean lines having an altered seed protein composition. Theoretical and Applied Genetics, 95, 1018-1023.

Hartweck, L. M., \& Osborn, T. C. (1997). Altering protein composition by genetically removing phaseolin from common bean seeds containing arcelin or phytohemagglutinin. Theoretical and Applied Genetics, 95, 1012-1017.

Hartweck, L. M., Vogelzang, R. D., \& Osborn, T. C. (1991). Characterization and comparison of arcelin seed protein variants from common bean. Plant Physiology, 97, 204-211.

Huesing, J. E., Shade, R. E., Chrispeels, M. J., \& Murdock, L. L. (1991). $\alpha$-Amylase inhibitor, not pytohemagglutinin, explains resistance of common bean seeds to cowpea weevil. Plant Physiology, 96, 993-996.

Ishimoto, M., \& Chrispeels, M. J. (1996). Protective mechanism of the Mexican bean weevil against high levels of alpha-amylase inhibitor in the common bean. Plant Physiology, 111, 393-401.

Ishimoto, M., \& Kitamura, K. (1989). Growth inhibitory effects of an a-amylase inhibitor from kidney bean, Phaseolus vulgaris (L.) on three species of bruchids (Coleoptera: Bruchidae). Applied Entomology and Zoology, 24, 281-286.

Ishimoto, M., Sato, T., Chrispeels, M. J., \& Kitamura, K. (1996). Bruchid resistance of transgenic azuki bean expressing seed amylase inhibitor of common bean. Entomologia Experimentalis et Applicata, 79, 309-315.

Janarthanan, S., \& Suresh, P. (2003). Insecticidal potential of wild bean seed protein, arcelin. Natural Product Radiance, 2, 243-245.

Janarthanan, S., Suresh, P., Radke, G., Morgan, D., \& Oppert, B. (2008). Arcelin from 
Indian wild pulse, L. purpureus and insecticidal activity in storage pests. Journal of Agricultural and Food Chemistry, 56, 1676 - 1682.

Janzen, D. H., Juster, H. B., \& Liener, I. E. (1976). Insecticidal action of the phytohemagglutinin in black beans on a bruchid beetle. Science, 192, 795-796.

Kornegay, J., \& Cardona, L. C. (1991). Inheritance of resistance to Acanthoscelides obtectus in a wild common bean accession crossed to commercial bean cultivars. Euphytica, 52, 103-111.

Kornegay, J., Cardona, C., \& Posso, C. E. (1993). Inheritance of resistance to Mexican bean weevil in common bean, determined by bioassay and biochemical tests. Crop Science, 33, 589-594.

Minney, B. H. P., Gatehouse, A. M. R., Dobie, P., Dendy, J., Cardona, C., \& Gatehouse, J. A. (1990). Biochemical bases of seed resistance to Zabrotes subfasciatus (bean weevil) in Phaseolus vulgaris (common bean): a mechanism for arcelin toxicity. Journal of Insect Physiology, 36, 757-761.

Mourey, L., Pedelacq, J.D., Brick, C., Fabre, C., Rouge, P., \& Samama, J. P. (1998). Crystal structures of the arcelin-1 dimer from Phaseolus vulgaris at $1.9 \mathrm{~A}^{\mathrm{o}}$ resolution. Journal of Biological Chemistry, 273, 12914-12922.

Osborn, T.C., Alexander, D.C., Sun, S. S. M., Cardona, C., \& Bliss, F. A. (1988). Insecticidal activity and lectin homology of arcelin seed protein. Science, 240, 207- 210.

Osborn, T. C., Blake, T., Gepts, P., \& Bliss, F. A. (1986). Bean arcelin. 2. Genetic variation, inheritance and linkage relationships of a novel seed protein of Phaseolus vulgaris L. Theoretical and Applied Genetics, 71, 847-855.

Osborn, T. C., Burow, M., \& Bliss, F. A. (1988). Purification and characterization of arcelin seed protein from common bean. Plant Physiology, 86, 399-405.

Paes, N. S., Gerhardt, I. R., Coutinho, M. V., Yokoyama, M., Santana, E., Harris, N., et al. (2000). The effect of arcelin-1 on the structure of the midgut of bruchid larvae and immunolocalization of the arcelin protein. Journal of Insect Physiology, 46, 393-402. 
Santino, S., Valesina, L., Lioi, A., Vitale, A., \& Bollini, R. (1991). Bean (Phaseolus vulgaris L.) seed lectins: a novel electrophoresis variant of arcelin. Plant Physiology, 10, 7-11.

Schroeder, H. E., Gollash, S., Moore, A., Tabe, L. M., Craig, S., Hardie, D., et al. (1995). Bean a-amylase inhibitor confers resistance to the pea weevil, Bruchus pisorum, in genetically engineered peas (Pisum sativum L.). Plant Physiology, 107, 12331239.

Shade, R. E., Schroeder, H. E., Pueyo, J. J., Tabe, L. M., Murdock, L. L., Higgins, T. J. V., et al. (1994). Transgenic pea seeds expressing the $\alpha$-amylase inhibitor of the common bean are resistant to bruchid beetles. Nature Bio/Technology, 12, 793796.

Sparvoli, F., \& Bollini, R. (1998). Arcelin in wild bean (Phaseolus vulgaris L.) seeds: sequence of arcelin 6 shows it is a member of the arcelins 1 and 2 subfamily. Genetic Resources and Crop Evolution, 45, 383-388.

Sparvoli, F., Lanave, C., Santucci, A., Bollini, R., \& Lioi, L. (2001). Lectin and lectin related proteins in lima bean (Phaseolus lunatus L.) seeds: biochemical and evolutionary studies. Plant Molecular Biology, 45, 587-597. 